\section{§16. High-precision Temperature Control and Stabilization Using a Cryocooler}

Hasegawa, Y. (Saitama Univ.), Iwamoto, A.

Cryocoolers without refrigerants have been used extensively to generate low temperatures for studying things such as superconducting magnets, solid-state physics and cryopumps. In particular, two-stage Gifford-McMahon (GM) cryocoolers are known for their high reliability, simple maintenance and low running costs compared to liquid-helium-based systems. ${ }^{1-5)}$ Although GM cryocoolers have many advantages for cooling a sample and controlling its temperature, they have one serious shortcoming, namely it is very difficult to control the temperature below $20 \mathrm{~K}$. The temperature fluctuations (nearly $20 \mathrm{mK}$ ) at low temperatures present a very serious problem when GM cryocoolers are used to control the temperature of an object. Recently, we used a GM cryocooler installed with fiberreinforced-plastic (FRP) dampers to achieve temperature control and stabilization to within a standard deviation of $0.21 \mathrm{mK}$ for a sample temperature of $4.2000 \mathrm{~K}$. This paper describes the temperature stabilization method employed and its performance.

Figure 1 shows a schematic diagram of the cryostat with a superconducting magnet cooled by another cryocooler. To reduce the temperature fluctuations, a FRP G10 damper (thickness: 0.5 or $1.0 \mathrm{~mm}$, diameter: $45 \mathrm{~mm}$; same diameter as the GM cryocooler head) was inserted between the copper block and the GM cryocooler head, and a low-temperature grease was applied to ensure thermal contact. Both were attached by screwing six stainless-steel screws into screw holes in the head. Figure 2 also shows the time series of the temperature of the copper block with a FRP damper installed. Minimum temperatures of about 3.3 and $3.6 \mathrm{~K}$ were achieved using $0.5 \mathrm{~mm}$-thick and $1.0-\mathrm{mm}$ thick FRP dampers, respectively. The measurement results show that the FRP damper reduced the temperature fluctuations.

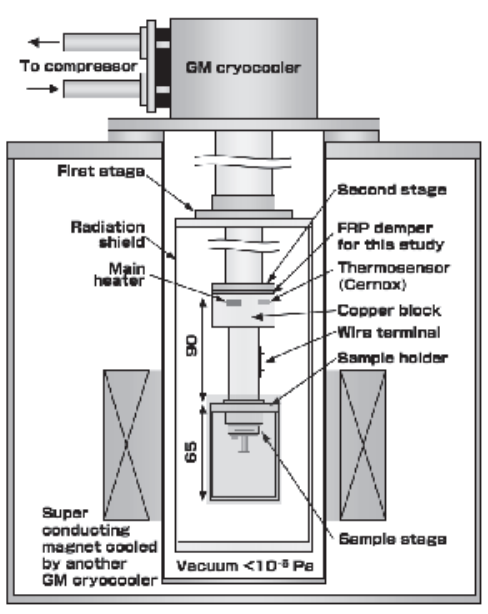

Fig. 1. Experimental setup of a cryostat using a GM cryocooler.

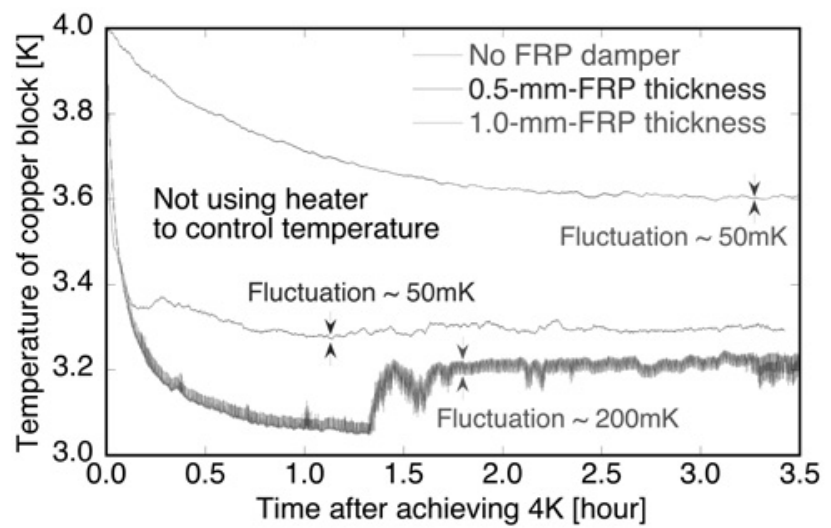

Fig. 2. Time series of temperature of a copper block attached to a GM cryocooler without using a heater; 0.5-mm-thick and 1.0-mm-thick FRP dampers inserted between the GM cooler head and the copper block (see Fig. 1).

1) H. O. McMahon and W. E. Gifford, Adv. Cryog. Eng., 5, 354 (1960)

2) H. O. McMahon, Cryogenics, 1, 65 (1960)

3) M. Nagao, T. Inaguchi, H. Yoshimura, T. Yamada, M. Iwamoto, Adv. Cryog. Eng. 35, 1251 (1990)

4) M. Nagao, T. Inaguchi, H. Yoshimura, S. Nakamura, T. Yamada, T. Matsumoto, S. Nakagawa, K. Moritsu, T. Watanage, Adv. Cryog. Eng. 39, 1327 (1994)

5) Y. Iwasa, Case Studies in Superconducting Magnets: Design and Operational Issues, Second Edition (Springer, 2009) 